\title{
Retrospective Analysis of Long-Term Survival in Very Elderly (Age $\geq 80$ ) Critically Ill Patients of a Medical Intensive Care Unit at a Tertiary Care Hospital in Korea
}

\author{
Seung Hun Lee, M.D., Ph.D. ${ }^{1}{ }^{(i)}$, Ju-Young Kim, M.D. ${ }^{2}$, Tae Hoon Kim, M.D., Ph.D. ${ }^{2}$, Sun Mi Ju, M.D. ${ }^{3}$, \\ Jung-Wan Yoo, M.D. ${ }^{3}$, Seung Jun Lee, M.D., Ph.D. ${ }^{3}$, Yu Ji Cho, M.D., Ph.D. ${ }^{3}$, Yi Yeong Jeong, M.D., \\ Ph.D. ${ }^{3}$, Jong Deog Lee, M.D., Ph.D. ${ }^{3}$ and Ho Cheol Kim, M.D., Ph.D. ${ }^{2}$ iD \\ ${ }^{1}$ Department of Internal Medicine, On Hospital, Busan, ${ }^{2}$ Department of Internal Medicine, Gyeongsang National University \\ Changwon Hospital, Gyeongsang National University School of Medicine, Changwon, ${ }^{3}$ Department of Internal Medicine, \\ Gyeongsang National University Hospital, Gyeongsang National University School of Medicine, Jinju, Korea
}

Background: The purpose of this study was to evaluate the long-term survival rates of very elderly (age $\geq 80$ ) critically ill patients admitted to a medical intensive care unit (MICU) at a regional tertiary-care hospital in Korea.

Methods: We retrospectively analyzed data from patients who survived after discharged from the MICU of our hospital. Survival rates at 90 days, 1 year, 2 years, and 3 years were assessed between patients age $\geq 80$ and those age $<80$. Survival status was evaluated using the National Health Insurance Service data.

Results: A total of 468 patients were admitted, 286 ( 179 males, 97 females; mean age, $70.18 \pm 13.2$ ) of whom survived and were discharged soon after their treatment. Among these patients, $69(24.1 \%)$ were age $\geq 80$ and $217(75.9 \%)$ were age $<80$. The 90-day, 1-year, 2-year, and 3-year survival rates of patients age $\geq 80$ were significantly lower than those in patients age $<80(50.7 \%, 31.9 \%, 15.9 \%$ and $14.5 \%$ vs. $68.3 \%, 54.4 \%, 45.6 \%$, and $40.1 \%$, respectively) ( $<<0.01)$. The Kaplan-Meier survival curves showed significantly lower survival rates in patients age $\geq 80$ than in those age $<80(\mathrm{p}=0.001)$.

Conclusion: The poor rates of long-term survival in very elderly (age $\geq 80$ ) and critically ill patients admitted to an ICU should be considered while managing and treating them.

Keywords: Very Elderly; Intensive Care Unit; Long-Term Survival

Address for correspondence: Ho Cheol Kim, M.D., Ph.D.

Department of Internal Medicine, Gyeongsang National University

Changwon Hospital, Gyeongsang National University School of

Medicine, 11 Samjeongja-ro, Seongsan-gu, Changwon 51472, Korea

Phone: 82-55-214-3730, Fax: 82-55-214-8618

E-mail: hockkim@gnu.ac.kr

Received: Apr. 25, 2019

Revised: Aug. 12, 2019

Accepted: Dec. 20, 2019

Published online: Mar. 10, 2020

(c) It is identical to the Creative Commons Attribution Non-Commercial License (http://creativecommons.org/licenses/by-nc/4.0/).

Copyright ( $) 2020$

The Korean Academy of Tuberculosis and Respiratory Diseases.

\section{Introduction}

The worldwide population is rapidly aging. Consequently, the number of elderly patients admitted to intensive care units (ICUs) is increasing as is the number of elderly patients age $>80$ years ${ }^{1,2}$. According to data reported by Lim et al. ${ }^{3}$, the number of ICU patients age $\geq 80$ years increased from $12.8 \%$ in 2005 to $20.7 \%$ in 2014 in Korea. A recent multicenter study in Korea has also reported that $22.1 \%$ of patients admitted to ICUs are elderly patients age over 80 years ${ }^{4}$.

In a recent study of elderly patients admitted to ICUs, the authors reported that ICU and in-hospital mortality rates do not differ significantly between patients aged more than 80 years and those younger than 80 years. The mortality rates of the ICU patients were $34.9 \%$ for patients age $>80$ years vs. 
$39.5 \%$ for those age $\leq 80$ years ${ }^{5}$. However, there have been few studies conducted on the long-term survival of patients admitted to ICUs in Korea. Recent study by Heo et al. ${ }^{6}$ reported long-term mortality according to age in patients admitted ICU using National Health Insurance data. In contrast, there is a relatively large amount of research data available outside of Korea. In one study in France, 2-year and 3-year survival rates of patients admitted to medical ICU for patients age $>80$ were $33 \%$ and $29 \%$, respectively ${ }^{7}$.

Because few studies have been conducted on the long-term survival of critically ill patients age $>80$ admitted to ICUs in Korea, the purpose of this study was to investigate the long-term survival and factors associated with mortality of such patients in the ICU of a single regional tertiary hospital in Korea.

\section{Materials and Methods}

All critically ill patients admitted to the medical ICU (MICU) at a single regional tertiary hospital (total hospital beds, 890; MICU beds, 13-15) between December 2011 and May 2014 were retrospectively studied. Admissions were determined by attending physicians according to general ICU admission criteria. Patient demographic and clinical characteristic data were prospectively collected and analyzed retrospectively. The following data were analyzed: sociodemographic data, including age, sex, body mass index (BMI), and chronic underlying disease; the reasons for admission; severity of illnesses, as measured by the Acute Physiology and Chronic Health Evaluation II (APACHE II) ${ }^{8}$ and Sequential Organ Failure Assessment (SOFA) ${ }^{9}$ systems at admission; duration of mechanical ventilation (MV); length of ICU and in-hospital stays, and outcome data, including survival status in ICU and at in-hospital. Patients were excluded if they were admitted due to acute coronary syndrome, drug overdoses, or acute cerebrovascular disease and age less than 18 years.

Weaning failure is defined as the failure to pass a spontaneous breathing trial or the need for reintubation within 48 hours following extubation and when blood transfusion is restricted to packed red cell transfusion.

Survival at 90th day, 1 year, 2 years, and 3 years were evaluated in patients who were admitted to the ICU and discharged from the hospital. The survival status of a patient was assessed based on National Health Insurance Corporation's medical insurance standards. A patient's death was evaluated by the cessation of medical insurance, and date of death was determined as the date of cessation. This study was approved by the institutional review board of the hospital (GNUCH-2018-10-011). The patients' informed consent for the study was waived due to the retrospective nature of the study.

The data are presented as mean \pm standard deviation and median with an interquartile range. Categorical data are presented as frequencies and percentages. Independent $\mathrm{t}$ test (continuous variables) and chi-square test (categorical variables) results were compared between patients age $\geq 80$ patients and those age $<80$. Survival curves were estimated by the Kaplan-Meier method, and with a log-rank test. Multivariate Cox proportional hazard regression models were used to evaluate factors associated with mortality in patients at 1 year after discharge. We choose the factor when univariate analysis showed p-value less than 0.05 or factor assumed with cause of death. A p-value of $<0.05$ was considered to be statistically significant for all tests. All statistical analyses were performed using SPSS version 25.0 (IBM Corp., Armonk, NY, USA) for Windows (Microsoft Corporation, Redmond, WA, USA).

\section{Results}

\section{Baseline clinical characteristics of the patients who survived}

A total of 468 patients (306 male, 162 female; mean age, $68.6 \pm 13.9$ years) were enrolled. Among these, 286 patients (179 male, 97 female; mean age, $70.18 \pm 13.2$ years) survived and were discharged. The baseline characteristics were listed in Table 1.

\section{Comparison of clinical characteristics between patients age $\geq 80$ and those age $<80$}

Among all patients survived, 69 (24.1\%) were age $\geq 80$ and $217(75.9 \%)$ were age $<80$. There were more males among patients age $<80$ than among those age $\geq 80(66.4 \%$ vs. $50.7 \%$, $\mathrm{p}=0.019$ ). BMI and SOFA scores at admission were higher in patients age $<80$ than in those age $\geq 80$ (BMI: $21.6 \pm 3.76$ vs. $20.6 \pm 3.4, \mathrm{p}=0.041$; SOFA score: $6.9 \pm 3.93$ vs. $5.55 \pm 3.23$, $\mathrm{p}=0.005$ ). Among underlying diseases, diabetes was more common in patients age $<80$ than in those age $\geq 80$ ( $34.6 \%$ vs. $21.7 \%$, $\mathrm{p}=0.046$ ). Moreover, heart disease was less common in patients age $<80$ than in those age $\geq 80$ ( $17.5 \%$ vs. $29 \%$, $\mathrm{p}=0.039$ ). Transfusion requirements were more common in patients age $<80$ than in those age $\geq 80$ ( $41.4 \%$ vs. $27.4 \%$, $\mathrm{p}=0.02)$.

\section{Comparison of the clinical outcomes and the differences in survival rates between patients age $\geq 80$ and those age $<80$}

Regarding clinical outcomes, the durations of hospital stay were longer for patients age $<80$ than for those age $\geq 80$ ( $27.95 \pm 39.63$ days vs. $18.17 \pm 15.45$ days, $\mathrm{p}=0.001)$. The 90 -day, 1-year, 2-year, and 3-year survival rates of patients age $\geq 80$ were $50.7 \%, 31.9 \%, 15.9 \%$, and $14.5 \%$, respectively, and the corresponding survival rates in patients age $<80$ were $68.3 \%$, $54.4 \%, 45.6 \%$, and $40.1 \%$, respectively $(\mathrm{p}<0.05)$ (Table 2$)$. The 
Table 1. Baseline characteristics of enrolled 286 survived patients

\begin{tabular}{|c|c|c|c|c|}
\hline \multirow{2}{*}{ Characteristic } & \multirow{2}{*}{$\begin{array}{c}\text { Total } \\
(n=286)\end{array}$} & \multicolumn{2}{|c|}{ Age (yr) } & \multirow{2}{*}{ p-value } \\
\hline & & $\geq 80(n=69)$ & $<80(n=217)$ & \\
\hline Age, yr & $70.18 \pm 13.2$ & $84.1 \pm 3.6$ & $65.7 \pm 12.0$ & 0.000 \\
\hline Male sex & $179(62.6)$ & $35(50.7)$ & $144(66.4)$ & 0.019 \\
\hline BMI, $\mathrm{kg} / \mathrm{m}^{2}$ & $21.4 \pm 3.7$ & $20.6 \pm 3.42$ & $21.6 \pm 3.76$ & 0.041 \\
\hline APACHE II score & $16.6 \pm 7.78$ & $15.7 \pm 7.39$ & $16.9 \pm 7.89$ & 0.214 \\
\hline SOFA score & $6.6 \pm 3.8$ & $5.55 \pm 3.23$ & $6.90 \pm 3.93$ & 0.005 \\
\hline Diabetes mellitus & $90(31.4)$ & $15(21.7)$ & $75(34.6)$ & 0.046 \\
\hline Heart disease & $58(20.3)$ & $20(29)$ & $38(17.5)$ & 0.039 \\
\hline Liver disease & $24(8.3)$ & $3(4.3)$ & $21(9.7)$ & 0.164 \\
\hline Renal disease & $56(19.6)$ & $8(11.6)$ & $48(22.1)$ & 0.055 \\
\hline Malignant disease & $29(10.1)$ & $3(4.3)$ & $26(12.0)$ & 0.067 \\
\hline Cerebrovascular disease & $36(12.6)$ & $7(10.1)$ & $29(13.4)$ & 0.483 \\
\hline Severe sepsis/septic shock & $74(25.8)$ & $12(17.6)$ & $62(28.7)$ & 0.262 \\
\hline ARDS & $33(11.5)$ & $7(10.1)$ & $26(12.0)$ & 0.677 \\
\hline MV (invasive) & $273(95.4)$ & $68(98.6)$ & $205(94.5)$ & 0.156 \\
\hline Weaning failure & $37(12.9)$ & $11(15.9)$ & $26(12.0)$ & 0.393 \\
\hline Unplanned extubation & $25(8.7)$ & $7(10.1)$ & $18(8.3)$ & 0.636 \\
\hline Tracheostomy & $33(11.5)$ & $4(6.3)$ & $29(9.7)$ & 0.511 \\
\hline Reintubation & $30(10.4)$ & $8(11.6)$ & $22(10.1)$ & 0.506 \\
\hline Renal replacement therapy & $45(15.7)$ & $8(11.6)$ & $37(17.1)$ & 0.278 \\
\hline Transfusion & $86(30.1)$ & $13(18.8)$ & $73(33.6)$ & 0.020 \\
\hline ECMO & $3(1.0)$ & $0(0)$ & $3(1.4)$ & 0.618 \\
\hline
\end{tabular}

Values are presented as mean \pm SD or number $(\%)$.

BMI: body mass index; APACHE II: Acute Physiology and Chronic Health Evaluation II; SOFA: Sequential Organ Failure Assessment; ARDS: acute respiratory distress syndrome; MV: mechanical ventilation; ECMO: extracorporeal membrane oxygenation.

Table 2. Comparison of outcome and survival rate between age $\geq 80$ and age $<80$ among 286 survived patients

\begin{tabular}{|c|c|c|c|c|}
\hline \multirow{2}{*}{ Characteristic } & \multirow{2}{*}{$\begin{array}{c}\text { Total } \\
(n=286)\end{array}$} & \multicolumn{2}{|c|}{ Age } & \multirow{2}{*}{ p-value } \\
\hline & & $\geq 80(n=69)$ & $<80(\mathrm{n}=217)$ & \\
\hline Duration of MV, day (median, interquartile range) & $6.5(8.9)$ & $7(8.8)$ & $6(9)$ & 0.131 \\
\hline ICU stay, day (median, interquartile range) & $5.5(9.8)$ & $6(10)$ & $5(9.5)$ & 0.084 \\
\hline Hospital stay, day (median, interquartile rage) & $20.5(20.3)$ & $18(13.5)$ & $23(27)$ & 0.001 \\
\hline Survival, 90th day & $183(63.9)$ & $35(50.7)$ & $148(68.2)$ & 0.010 \\
\hline Survival, 1 year & $140(48.9)$ & $22(31.9)$ & $118(54.4)$ & 0.001 \\
\hline Survival, 2 years & $110(38.4)$ & $11(15.9)$ & $99(45.6)$ & $<0.001$ \\
\hline Survival, 3 years & $97(33.9)$ & $10(14.5)$ & $87(40.1)$ & $<0.001$ \\
\hline
\end{tabular}

Values are presented as median (interquartile range) or number (\%).

MV: mechanical ventilation; ICU: intensive care unit. 


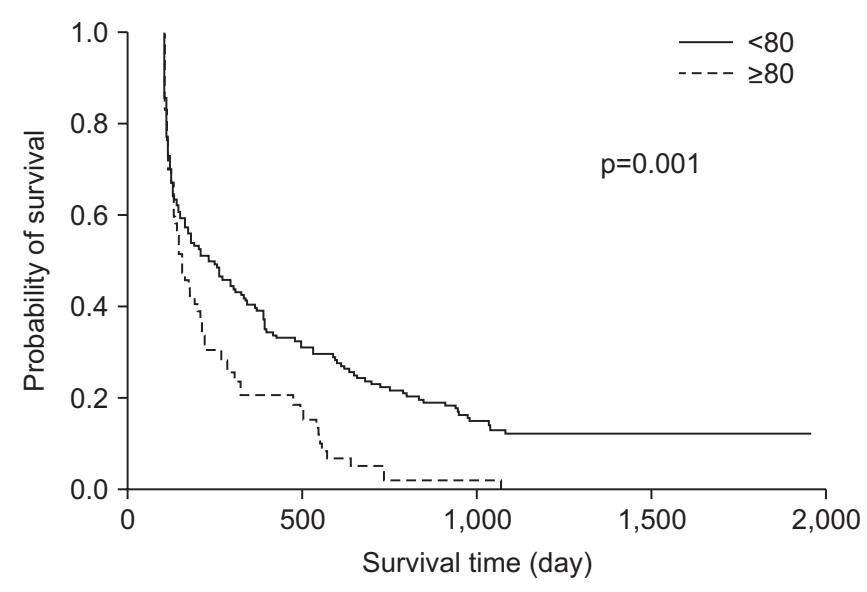

Figure 1. Kaplan-Meier survival curve between patients age $\geq 80$ and those age $<80$.

Kaplan-Meier curves and log-rank tests for 1-year survival of patients age $\geq 80$ showed significantly lower survival rates than those age $<80(\mathrm{p}=0.001)$ (Figure 1$)$.

\section{Comparison of clinical characteristics between survivors and non-survivors 1 year after discharge among the 69 patients age $\geq 80$}

Characteristics of survivors and non-survivors 1 year after discharge among the 69 patients age $\geq 80$ are summarized in Table 3. The proportions of males and BMI scores were not significantly different between survivors and non-survivors. However, the proportion of BMIs $\leq 18$ was significantly different between survivors and non-survivors $(4.5 \%$ vs. $27.7 \%$, $\mathrm{p}=0.026$ ). No difference was found between APACHE II and SOFA scores at admission between survivors and non-survivors. Regarding underlying disease and the cause of admission, the proportion of patients presenting with severe sepsis and septic shock was not significantly different between survivors and non-survivors. Although ICU and hospital stays were not significantly different between survivors and non-survivors, the durations of MV were significantly longer in nonsurvivors than in survivors ( $5.67 \pm 4.53$ vs. $9.66 \pm 8.52, \mathrm{p}=0.015$ ). The MV weaning failure and unplanned extubation were not significantly different between survivors and non-survivors. Requirements for renal replacement therapy, extracorporeal membrane oxygenation, and transfusions were not significantly different between survivors and non-survivors.

\section{Factors associated with mortality in patients 1 year after discharge}

The sociodemographic data, including age, sex, BMI, underlying disease, severity of illnesses and durations of $\mathrm{MV}$, and length of ICU stay were not associated with a risk of mortality
Table 3. Comparison of clinical characteristics between survivors and non-survivors 1 year after discharge among the 69 patients age $\geq 80$

\begin{tabular}{|lccc|}
\hline \multicolumn{1}{|c}{ Characteristic } & $\begin{array}{c}\text { Survivors } \\
(\mathbf{n}=\mathbf{2 2})\end{array}$ & $\begin{array}{c}\text { Non- } \\
\text { survivors } \\
(\mathbf{n}=\mathbf{4 7})\end{array}$ & p-value \\
\hline Age, yr & $83.95 \pm 3.58$ & $84.17 \pm 3.66$ & 0.819 \\
Male sex & $11(50.0)$ & $24(51.1)$ & 0.934 \\
BMI, kg/m ${ }^{2}$ & $21.39 \pm 2.90$ & $20.23 \pm 3.61$ & 0.161 \\
BMI, $\leq 18 \mathrm{~kg} / \mathrm{m}^{2}$ & $1(4.5)$ & $13(27.7)$ & 0.026 \\
BMI, $25 \mathrm{~kg} / \mathrm{m}^{2}$ & $4(18.2)$ & $3(6.4)$ & 0.130 \\
APACHE II score & $15.64 \pm 8.30$ & $15.72 \pm 7.03$ & 0.966 \\
SOFA score & $5.59 \pm 3.17$ & $5.53 \pm 3.29$ & 0.964 \\
Diabetes mellitus & $3(13.6)$ & $12(25.5)$ & 0.264 \\
Heart disease & $4(18.2)$ & $16(34.0)$ & 0.176 \\
Liver disease & $0(0)$ & $3(6.4)$ & 0.226 \\
Renal disease & $2(9.1)$ & $6(12.8)$ & 0.657 \\
Malignant disease & $0(0)$ & $3(6.4)$ & 0.226 \\
Cerebrovascular disease & $1(4.5)$ & $6(12.8)$ & 0.292 \\
Severe sepsis/septic shock & $8(36.4)$ & $8(17.4)$ & 0.936 \\
ARDS & $0(0)$ & $7(14.9)$ & 0.056 \\
MV (invasive) & $21(95.5)$ & $47(100)$ & 0.141 \\
Weaning failure & $2(9.1)$ & $9(19.1)$ & 0.288 \\
Unplanned extubation & $4(18.2)$ & $3(6.4)$ & 0.130 \\
Tracheostomy & $1(4.5)$ & $3(6.4)$ & 0.315 \\
Reintubation & $3(13.6)$ & $5(10.6)$ & 0.717 \\
Renal replacement therapy & $2(9.1)$ & $6(12.8)$ & 0.657 \\
Transfusion & $2(9.1)$ & $11(23.4)$ & 0.156 \\
ECMO & $1(4.5)$ & $1(17.0)$ & 0.152 \\
Duration of MV, day & $4 \pm 7$ & $9 \pm 8$ & 0.015 \\
ICU stay, day & $7.5 \pm 26$ & $17 \pm 12$ & 0.102 \\
Hospital stay, day & & & \\
\hline
\end{tabular}

Values are presented as mean \pm SD or number (\%).

BMI: body mass index; APACHE II: Acute Physiology and Chronic Health Evaluation II; SOFA: Sequential Organ Failure Assessment; ARDS: acute respiratory distress syndrome; MV: mechanical ventilation; ECMO: extracorporeal membrane oxygenation; ICU: intensive care unit.

at 1 year after discharge among 69 patients age $\geq 80$, according to the multivariate Cox regression analysis of hazard ratios (Table 4).

\section{Discussion}

This study evaluated long-term survival in critically ill pa- 
Table 4. Cox regression hazard ratios by multivariate analysis of 69 non-survivors age $\geq 80$, obtained 1 year after discharge

\begin{tabular}{|lcc|}
\hline \multicolumn{1}{|c}{ Variable } & HR $(\mathbf{9 5 \%}$ CI) & p-value \\
\hline Age & $1.005(0.910-1.110)$ & 0.918 \\
Male & $0.909(0.465-1.776)$ & 0.779 \\
APACHE II & $13.048(0.991-1.107)$ & 0.099 \\
BMI, $\leq 18 \mathrm{~kg} / \mathrm{m}^{2}$ & $1.606(0.801-3.221)$ & 0.182 \\
Malignant disease & $0.478(0.119-1.916)$ & 0.297 \\
Heart disease & $1.293(0.604-2.768)$ & 0.264 \\
Cerebrovascular disease & $0.864(0.119-1.916)$ & 0.864 \\
ARDS & $2.352(0.976-5.669)$ & 0.057 \\
Duration of MV, day & $1.066(0.988-1.149)$ & 0.099 \\
Duration of ICU stay, day & $0.977(0.907-1.054)$ & 0.552 \\
\hline
\end{tabular}

HR: hazard ratio; CI: confidence interval; APACHE: Acute Physiology and Chronic Health Evaluation; BMI: body mass index; ARDS: acute respiratory distress syndrome; MV: mechanical ventilation; ICU: intensive care unit.

tients admitted to the ICU and showed poorer long-term survival in patients age $\geq 80$ than in those age $<80$. Despite the increasing number of very elderly patients admitted to ICUs ${ }^{3-5}$, there have been few reports regarding long-term survival of the very elderly and critically ill patients in Korea. A recent nationwide cohort study reported that, during the study period from 2003 to 2010 , the proportion of patients age $\geq 70$ had increased by an average of 3.6 years per study year, with 90-day, 1-year, and 3 -year mortality rates in patients age $\geq 80$ patients being $36.1 \%, 50.7 \%$, and $65.9 \%$, respectively ${ }^{6}$. In contrast to the lack of published data in Korea, there have been multiple studies investigating the long-term outcomes in very elderly and critically ill patients admitted to ICUs in other countries. Roch et al. ${ }^{10}$ have investigated the 2-year mortality of ICU patients age $>80$ in France. Their results showed that, of 133 patients over 80 years old, 1-year and 2-year mortality rates after admission were $72 \%$ and $78 \%$, respectively. One study conducted in Norway reported a mortality rate of approximately $60 \%$ for patients age $>80$ in a mixed ICU ${ }^{11}$. Overall, $40 \%-60 \%$ mortality rates have been reported in previous studies ${ }^{12-18}$, similar to results of the present study.

Factors associated with long-term mortality in the very elderly and critically ill patients have been studied. Roch et al. ${ }^{10}$ have studied factors associated with mortality at 2 years after hospital discharge from medical ICUs in patients age $>80$. They reported that more severe underlying diseases as classified by McCabe score ${ }^{19}$ and higher results of the simplified Acute Physiologic Score II representing more severe critical illnesses were independently associated with the 2-year mortality rate after hospital discharge. Similarly, Torres et al. have reported that comorbid illness scored with the Charl- son Comorbidity Index ${ }^{20}$ was the strongest predictor of longterm survival in critically ill older patients. In a recent Korean study assessing long-term outcomes in ICU patients, higher comorbidity scores and male sex were associated with longterm higher mortality rates in these patients ${ }^{6}$. In other studies evaluating the factors associated with long-term mortality in elderly critically ill patients, Lown et $\mathrm{al}^{21}$ have reported that in addition to age, the need for MV and the presence of acute renal failure are associated with mortality within 12 months after discharge in patients age $>80$. Regarding causes of admission, respiratory failure, and head injuries have been reported as predictors of 1-year mortality in a mixed ICU population of patients age $80^{11}$. Other studies have demonstrated that low hemoglobin and high creatinine concentrations are independent risk factors for long-term mortality ${ }^{12,13}$. Some studies have reported that the duration of ICU stay may be associated with long-term mortality. Laupland et al. ${ }^{22}$ have reported that staying in the surgical and cardiovascular ICUs for more than 14-day results in high mortality rates than shorter ICU stays. Longer ICU stay may present poor performance status at the time of discharge. Thus, it might be associated with poor longterm outcomes of critically ill patients.

Quality of life is a very important aspect in surviving patients after ICU discharge. We tend to expect a poor quality of life for critically ill patients, especially for the very elderly population. One study assessing 278 patients age $\geq 80$ who were admitted to ICUs showed that quality of life evaluated using the EuroQol-5 Dimension (EQ-5D) questionnaire revealed a significant decrease with age, including increasing problems with mobility, self-care, and activities of daily living ${ }^{17}$. In addition, Pavoni et al. ${ }^{14}$ have demonstrated that medical and orthopedic patients have poorer quality of life than surgical patients.

This study has some limitations. First, it was conducted using a single hospital's data and limited to medical ICU patients. Second, we were unable to determine the quality of life or assistance given in nursing care facilities after discharge. Third, whether or not patients had died or survived was assessed only based on medical insurance data. Therefore, the exact time of death might have been somewhat biased in this study. Fourth, as described above, functional status at the time of admission rather than severity of illness is more predictable and an important factor to evaluate long-term outcomes. However, we assessed only the underlying disease rather than the general function status.

Despite these limitations, our study is important in that it assesses the long-term survival in very elderly and critically ill patients admitted to the ICU. This information is especially important in light of the growing elderly population in Korea. However, a future nationwide study is necessary to determine factors associated with long-term outcomes and quality of life. 


\section{Authors' Contributions}

Conceptualization: Kim HC. Methodology: Lee SH, Kim HC. Formal analysis: Kim HC. Data curation: Lee SH, Kim HC. Software: Lee SH, Kim HC. Validation: Lee SH, Kim HC. Investigation: Lee SH, Kim JY, Kim TH, Ju SM, Yoo JW, Lee SJ, Cho YJ, Jeong YY, Lee JD, Kim HC. Writing - original draft preparation: Lee SH. Writing - review and editing: Kim HC. Approval of final manuscript: all authors.

\section{Conflicts of Interest}

No potential conflict of interest relevant to this article was reported.

\section{Funding}

No funding to declare.

\section{References}

1. Manton KG, Vaupel JW. Survival after the age of 80 in the United States, Sweden, France, England, and Japan. N Engl J Med 1995;333:1232-5.

2. Boumendil A, Guidet B. Elderly patients and intensive care medicine. Intensive Care Med 2006;32:965-7.

3. Lim JU, Lee J, Ha JH, Kang HH, Lee SH, Moon HS. Demographic changes in intensive care units in Korea over the last decade and outcomes of elderly patients: a single-center retrospective study. Korean J Crit Care Med 2017;32:164-73.

4. Park J, Jeon K, Chung CR, Yang JH, Cho YH, Cho J, et al. A nationwide analysis of intensive care unit admissions, 20092014: the Korean ICU National Data (KIND) study. J Crit Care 2018;44:24-30.

5. Lee SH, Lee TW, Ju S, Yoo JW, Lee SJ, Cho YJ, et al. Outcomes of very elderly ( $\geq 80$ years) critical-ill patients in a medical intensive care unit of a tertiary hospital in Korea. Korean J Intern Med 2017;32:675-81.

6. Heo J, Hong Y, Han SS, Kim WJ, Kwon JW, Moon KW, et al. Changes in the characteristics and long-term mortality rates of intensive care unit patients from 2003 to 2010: a nationwide population-based cohort study performed in the Republic of Korea. Acute Crit Care 2018;33:135-45.

7. Boumendil A, Maury E, Reinhard I, Luquel L, Offenstadt G, Guidet B. Prognosis of patients aged 80 years and over admitted in medical intensive care unit. Intensive Care Med 2004; 30:647-54.

8. Knaus WA, Draper EA, Wagner DP, Zimmerman JE. APACHE II: a severity of disease classification system. Crit Care Med
1985;13:818-29.

9. Le Gall JR, Lemeshow S, Saulnier F. A new Simplified Acute Physiology Score (SAPS II) based on a European/North American multicenter study. JAMA 1993;270:2957-63.

10. Roch A, Wiramus S, Pauly V, Forel JM, Guervilly C, Gainnier $\mathrm{M}$, et al. Long-term outcome in medical patients aged 80 or over following admission to an intensive care unit. Crit Care 2011;15:R36.

11. Andersen FH, Flaatten H, Klepstad P, Romild U, Kvale R. Long-term survival and quality of life after intensive care for patients 80 years of age or older. Ann Intensive Care 2015;5: 53.

12. de Rooij SE, Govers A, Korevaar JC, Abu-Hanna A, Levi M, de Jonge E. Short-term and long-term mortality in very elderly patients admitted to an intensive care unit. Intensive Care Med 2006;32:1039-44.

13. Mukhopadhyay A, Tai BC, See KC, Ng WY, Lim TK, Onsiong $\mathrm{S}$, et al. Risk factors for hospital and long-term mortality of critically ill elderly patients admitted to an intensive care unit. Biomed Res Int 2014;2014:960575.

14. Pavoni V, Gianesello L, Paparella L, Buoninsegni LT, Mori E, Gori G. Outcome and quality of life of elderly critically ill patients: an Italian prospective observational study. Arch Gerontol Geriatr 2012;54:e193-8.

15. Somme D, Maillet JM, Gisselbrecht M, Novara A, Ract C, Fagon JY. Critically ill old and the oldest-old patients in intensive care: short- and long-term outcomes. Intensive Care Med 2003;29:2137-43.

16. Becker S, Muller J, de Heer G, Braune S, Fuhrmann V, Kluge S. Clinical characteristics and outcome of very elderly patients $\geq 90$ years in intensive care: a retrospective observational study. Ann Intensive Care 2015;5:53.

17. Ferrao C, Quintaneiro C, Camila C, Aragao I, Cardoso T. Evaluation of long-term outcomes of very old patients admitted to intensive care: survival, functional status, quality of life, and quality-adjusted life-years. J Crit Care 2015;30:1150.

18. Mahul P, Perrot D, Tempelhoff G, Gaussorgues P, Jospe R, Ducreux JC, et al. Short- and long-term prognosis, functional outcome following ICU for elderly. Intensive Care Med 1991;17: 7-10.

19. McCabe WR, Jackson GG. Gram-negative bacteremia: I. etiology and ecology. Arch Intern Med 1962;110:847-55.

20. Charlson ME, Pompei P, Ales KL, MacKenzie CR. A new method of classifying prognostic comorbidity in longitudinal studies: development and validation. J Chronic Dis 1987;40: 373-83.

21. Lown DJ, Knott J, Rechnitzer T, Maclsaac C. Predicting shortterm and long-term mortality in elderly emergency patients admitted for intensive care. Crit Care Resusc 2013;15:49-55.

22. Laupland KB, Kirkpatrick AW, Kortbeek JB, Zuege DJ. Longterm mortality outcome associated with prolonged admission to the ICU. Chest 2006;129:954-9. 